\title{
MIRADAS CRÍTICAS, TRAVESÍA EDITORIAL, ARQUEO PROVISORIO. ITINERARIOS SOBRE PRÁCTICAS Y DISCURSOS LITERARIOS DEL SIGLO XIX LATINOAMERICANO
}

\section{Carlos Hernán Sosa}

Universidad Nacional de Salta Consejo Nacional de Investigaciones Científicas y Técnicas, CONICET Argentina chersosa@hotmail.com ORCID: 0000-000 I-725I-8093

Fecha de recepción: 02/07/2021 | Fecha de aceptación: 18/07/2021

Resumen: A partir de los primeros veinticinco volúmenes de la revista Anclajes, se revisa el desarrollo de los estudios sobre el siglo XIX en la crítica literaria de la Argentina. Estos estudios alcanzaron una fuerte impronta y visibilidad durante la década de 1990 y mediados de la siguiente; para sufrir, luego, un estancamiento notorio. El viraje en estos intereses parece ser casi una consecuencia previsible ante la enorme afluencia de abordajes críticos focalizados en la situación de la literatura latinoamericana más reciente.

Palabras clave: crítica literaria; siglo XIX; literatura argentina; literatura latinoamericana.

\section{Critical glances, editorial journey, provisional archiving. Itineraries on literary practices and discourses of the Latin American 19th century}

Abstract: I review the development of studies on the nineteenth century in literary criticism in Argentina from the first twenty-five volumes of Anclajes. These studies achieved a strong imprint and visibility during the 1990s and mid-1990s; to suffer, later, a notorious stagnation. The shift in these interests seems to be almost a foreseeable 
consequence given the enormous influx of critical approaches focused on the situation of the most recent Latin American literature.

Keywords: Literary criticism; XIX century; Argentine literature; Latin American literature.

\section{Olhares críticos, jornada editorial, arquivo provisório. Itinerários de práticas e discursos literários do século XIX latino-americano}

Resumo: A partir dos primeiros vinte e cinco volumes da revista Anclajes, passa-se em revista o desenvolvimento dos estudos sobre a crítica literária na Argentina no século XIX. Esses estudos alcançaram uma forte marca e visibilidade durante os anos 1990 e meados dos anos 1990; sofrer, mais tarde, uma notória estagnação. A mudança nesses interesses parece ser uma consequência quase previsível, dado o enorme influxo de abordagens críticas focadas na situação da literatura latinoamericana mais recente.

Palavras chave: Crítica literária; século XIX; Literatura argentina; Literatura latinoamericana.

"[Como críticos, podemos] historiar el entrecruzamiento entre la historia y las literaturas sobre la base de esta afirmación: la literatura dice en su lenguaje lo que dice la historia pero, sin lugar a dudas, dice más".

Nicolás Rosa, Políticas de la crítica.

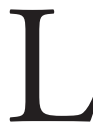

a publicación del primer número de Anclajes, en 1997, supuso el arranque de la revista en edición paralela a un momento importante en la historia reciente de los estudios dedicados a las culturas y literatura latinoamericanas que se configuraron durante el siglo XIX. Justamente, los estudios latinoamericanos sobre las culturas literarias decimonónicas alcanzaron una fuerte impronta y visibilidad durante la década de 1990 y mediados de la siguiente; para sufrir, luego, un estancamiento notorio, que se verifica en las relativamente pocas producciones actuales (libros y artículos académicos, proyectos de investigación o grupos de estudio, tesis de posgrado) abocadas con especificidad a esos temas. El viraje en estos intereses parece ser casi una consecuencia previsible ante la enorme afluencia de abordajes críticos focalizados en la situación de la literatura latinoamericana más reciente. Ello puede apreciarse, de manera muy clara, en los estudios sobre algunas zonas discursivas (las narrativas de dictadura y posdictadura, las escrituras de mujeres, algunos tratamientos temáticos del fantasy -como el terror y lo distópico-, las textualidades híbridas/ fronterizas - como la crónica, el testimonio o la canción-, todo el espectro del giro autobiográfico, etc.), encaminados desde perspectivas teóricas 
que se instalaron cómodamente con fuerte presencia en el espacio crítico (posestructuralismos, estudios culturales, sociología de la cultura, biopolítica, materialismo cultural, feminismos y sexualidades disidentes, estudios transatlánticos, (pos)(de)colonialismos, estudios sobre etnicidad y subalternidades, etc.).

En líneas generales, los estudios dedicados a corpus y problemáticas consagrados al siglo XIX -o, si queremos ser más precisos, al largo siglo XIX del que habla Eric Hobsbawm ${ }^{1}$, para emplear una noción que, a pesar de ajustarse mejor a órdenes procesuales occidentales, supera el fetichismo ineficiente de las cronológicas- privilegian las inevitables intersecciones con perspectivas de análisis de corte sociohistórico o sociocultural. De hecho, la problemática histórica funciona como una caja de resonancia inmediata y no negociable -a veces como una auténtica ortodoxia naturalizada- que resulta visible en muchos de los análisis encarados en el terreno literario cuando, por ejemplo, se abordan discursos y prácticas asociados a los nacionalismos, los imaginarios sociales, la prensa decimonónica, la emergencia incipiente de campos literarios, la ampliación del lectorado con los sectores populares e inmigratorios, las materialidades inherentes a los procesos de escritura y lectura, las formas de sociabilidad y asociacionismo de la cultura literaria, las representaciones y autofiguraciones de las actividades letradas (de varones y de mujeres), etc.

Dichas preferencias de análisis, no siempre, pero sí en muchos casos, han sufrido cierto adelgazamiento en varias de las tendencias dedicadas a las producciones literarias recientes, sobre todo en las de fines del siglo XX y comienzos del XXI. En la medida en que, si bien estas operaciones críticas no descartan por supuesto una reflexión sobre los vínculos con lo sociohistórico, sí de algún modo priorizan metodológicamente modos de lectura (sobre todo mediante la construcción de genealogías o de series literarias -siguiendo el magisterio de David Viñas y Josefina Ludmer-) y el rastreo eficiente de corpus ad hoc a las urgencias teóricas elegidas donde dicha preocupación se torna por momentos subsidiaria. Ello debido a que, por distintas razones, el acento crítico aparece direccionado por la apelación a una idea autosuficiente y medianamente estable de literatura -y esto aun cuando se analicen sus restos precarios "postautónomos"- y a las formas de entramado que la propia organización de las series literarias vendría a confirmar en su recorte, a partir de dichos presupuestos analíticos.

Es decir, que la pregunta por las porosas intermediaciones, donde -en verdadse negocian los significados según las relecturas ideológicamente demandantes que la literatura aporta sobre el contexto decimonónico, soportó sus previsibles mutaciones, al menos tal como imperaba en aquel momento de apogeo crítico

1 A fin de evitar la mención de repertorios bibliográficos que amenazan con el infinito, sólo señalo en el texto con pincelada gruesa autores y vertiente críticas, para que puedan ser identificados. Aun en los casos en que se dan mayores precisiones sobre alguna obra crítica en particular, creo haber sido lo suficientemente alusivo como para que el lector pueda identificarla desde el señalamiento indirecto. Cuando cito los artículos publicados en Anclajes, consigno solamente entre paréntesis el volumen y número de la revista y el año de publicación correspondientes. 
entre la década de 1990 y mediados de la del 2000. Lo hizo, entre otros motivos, porque las propias textualidades contemporáneas analizadas con prioridad permitían atenuar el eje de reflexión -o directamente prescindir de él- respecto de la propia construcción como objeto de estudio de la literatura; una operación crítica que resulta inexcusable, es mucho más compleja de asir para los estudios sobre el siglo XIX, y cuya resolución disciplinar depende, por cierto, de cómo arriesgar una interpretación sobre las tensiones vinculares entre materialidades verbales y contextos, entre prácticas y discursos. Por otra parte, además, muchos de estos reposicionamientos se introdujeron como remanente de las mismas alteraciones que -desde mediados del siglo XX- soportaba la concepción moderna de lo literario, cuestionada por los pensamientos filosóficos eurocéntricos sobre la posmodernidad y los relativismos culturales contestatarios. Las propias discursividades literarias -en una sección de las producciones latinoamericanas recientes, no en todo el conjunto- en clave autorreflexiva o intermedial se encaminaron hacia modos del decir más disruptivos, acicateados por los escarceos de las últimas avanzadas de la cultura global, donde hacían eclosionar las antiguas convenciones que acordábamos sobre la entidad y el estatus de lo literario y sus prácticas satelitales de producción, circulación y consumo -es decir, los lazos, también pactados, en relación con sus posibles contextos (de emergencia, de recepción, metacríticos, etc.)-.

En el panorama del campo de la crítica de estos años, si se contrastan los aparatos teóricos y las perspectivas de análisis empleados para estudiar las discursividades literarias latinoamericanas del siglo XIX, el conjunto parece acompañar todavía los acuerdos tácitos que dichas materialidades verbales constreñían, de algún u otro modo, como exponentes de las escaladas de (pre)modernidad que Latinoamérica -con toda su gama variopinta de espesores y discontinuidades temporales sobre las que advierte Ángel Rama- atravesó entre fines de la experiencia colonial y la modernización cultural de la transición al siglo XX. De modo que el discurso crítico, munido de un convencimiento especular y performativo, se amoldaba y transigía en explicar estos procesos. Y así, tal como las discursividades culturales decimonónicas avanzaron seguras de su rol en las políticas imaginarias y simbólicas de su momento sociohistórico, la crítica participaba con igual confianza en su tarea interpretativa, persuadida de la relevancia de un quehacer sobre el cual hoy -a la luz de la experiencia de estudios inscriptos en este mismo campo de estudio durante la última década- se vislumbran mayores escepticismos o se ha sincerado, al menos, una puesta al día de la vigilancia epistemológica sobre su propio métier.

La presencia de la agenda de los estudios literarios más relevantes, rastreable en el conjunto de contribuciones de artículos que abordaron el siglo XIX latinoamericano en estos veinticinco ańos de Anclajes, fue favoreciendo una retroalimentación que actualmente nos permite evaluar las intervenciones críticas que, desde esta publicación periódica, han ido nutriendo las demandas del campo especializado. En este sentido, pueden destacarse algunas de las vertientes de 
estudio que tuvieron cabida en la revista, apelando a dos factores interrelacionados: la renovación de la mirada crítica y la incorporación de nuevos objetos de estudio (o, en su defecto, la refundación epifánica de textos y autores que contaban con tradiciones metacríticas muy sedimentadas).

La emergencia de los nacionalismos es una línea de estudios que ha tenido diversas y recurrentes modulaciones en la historia de la crítica literaria argentina. En uno de sus últimos ciclos de rotación, es posible reconoce una inscripción germinal a partir del trabajo pionero que Carlos Altamirano y Beatriz Sarlo ofrecieron sobre la experiencia del nacionalismo cultural del Centenario y la diáspora de recorridos posteriores que se fueron concatenando (Miguel Dalmaroni y Fernando Degiovanni). Asimismo, toda una tradición fue instalándose también en lo que refiere al siglo XIX latinoamericano, tendiente a la refuncionalización de utillajes teóricos y conceptuales - pensados para otras experiencias occidentales (Benedict Anderson, Eric Hobsbawm y Terence Ranger, Bronislaw Baczko, Homi Bhabha, etc.)- que permitieran revisar -con los matices del caso- los procesos de configuración identitaria de los nacionalismos latinoamericanos. $\mathrm{O}$, en otra veta, prevaleció el trazado de perspectivas reflexivas de manera más situada en las propias materialidades literarias, en las intervenciones críticas de Hugo Achugar, Ricardo Kaliman, entre otros. Dicha orientación también puede identificarse en los estudios de Doris Sommer, desde donde se indaga el acompañamiento particular de un género como la novela $-\mathrm{y}$ la tematización de la familia- en la construcción imaginaria de las naciones latinoamericanas.

Precisamente, este es uno de los nichos críticos más cubierto -para problematizar los nacionalismos desde ambas tendencias- dentro del conjunto de contribuciones sobre el siglo XIX en Anclajes. Así, los artículos de Paula Andrea Marín Colorado (2013) - "La utopía de la nación ilustrada en la novela El mudo. Secretos de Bogotá por un bogotano (1848) de Eladio Vergara y Vergara" (Vol. 17, N. $\left.{ }^{\circ} 1\right)$ - y de María Pía Bruno (2009) -"Configuración de la patria y de las letras cubanas en el siglo diecinueve" (Vol. 13, N. ${ }^{\circ} 13$ )- se inscriben en dicha indagación crítica, orientada a pensar cómo el afianzamiento genérico de la novela, en Colombia y Cuba, puede analizarse como contribución discontinua en el proyecto de discusión sobre los modelos de nación en danza. La perspectiva que ofrece el folletín de Vergara y Vergara permite reconocer una propuesta de nación pro civilizatoria, con visos excluyentes, en la que perviven todavía los sesgos rígidos de una sociedad de Antiguo Régimen heredados de la colonia; mientras que la experiencia cubana se recompone a partir del itinerario de algunos representantes de formaciones culturales, vinculadas con el reformismo liberal ilustrado, donde se discutían temáticas como la esclavitud y lo étnico -en tanto debates inseparables de una postulación identitaria para el país-y el rol del letrado y la producción literaria -como factores coadyuvantes para la programación de un imaginario patriótico en Cuba-. El materialismo cultural inglés (desde la vertiente de Raymond Williams) se hace presente en el trabajo de Andrea Bocco (2009), "Tensiones entre proyectos intelectuales, políticas estatales y emergencia 
de las masas en los cancioneros populares" (Vol. 13, N. ${ }^{\circ} 13$ ), en uno de cuyos tramos se problematiza la instancia de configuración tensionada de lo popular que los cancioneros argentinos ponen de relieve-casi como pervivencia residual de algunos aggiornamentos letrados realizados sobre la gauchesca y el criollismo de la transición al siglo XX-, en una operación de políticas culturales encaradas al calor de las necesidades y urgencias de los folklorólogos desde fines del siglo XIX y prácticamente a lo largo de todo el siglo XX. La tradición crítica sobre el nacionalismo cultural del Centenario, donde las categorías williamsianas resultaron fructíferas para pensar dinámicamente este momento como una estructura de sentir, se prolonga en esta contribución hacia el análisis de las tensiones que dos proyectos políticos de masas -el yrigoyenismo y el peronismo- inscribieron en relación con la volátil inscripción de lo popular "reacondicionada" desde la esfera de los estudios sobre folklore.

Tres artículos acercaron también, durante estos años, análisis próximos ya que continuaban indagando procesos de construcción de los nacionalismos, esta vez a partir de un punto de intersección complejo como es la presencia del indio. En el caso del artículo de Hernán Pas (2012), “¿Ecos de Lautaro?: las lenguas indígenas como patrimonio cultural del nacionalismo criollo en el siglo XIX" (Vol. 16, N. ${ }^{\circ}$ 2), se examinan formas de apropiación "cientificistas" e institucionalizantes de las lenguas de los pueblos originarios, por parte de las elites porteña y santiaguina, en el contexto de reformulación del aporte indígena a las idiosincrasias identitarias de las naciones respectivas. Por su parte, Sofía de Mauro (2020), en "La imposibilidad moral de la existencia del drama: notas sobre la controversia del Ollantay" (Vol. 24, N.`1), revisa los altercados en torno del drama Ollantay y la literatura americana a partir de la intervención crítica de Bartolomé Mitre, subrayando las andaduras en materia de apropiación de esta discursividad compleja, donde se polemizó sobre orígenes, religaciones simbólicas y proto lingüísticas con los pueblos originarios. Por último, Pablo Hurtado Ruiz y Luis Hachim Lara, en "Las Memorias de Túpac Amaru y la Autobiografía de Manzano en el proyecto nacional criollo" (Vol. 24, N. ${ }^{\circ}$ 1), analizan las estrategias de apropiación de la escritura de un indígena y un esclavo al ser cooptadas por las programáticas criollas, mediante el paradójico proceso de "blanqueamiento" ideológico y "narcotización" de la conflictividad social, que ensayaron con cálculo deliberado las narrativas nacionales.

Otra de las vertientes críticas que mayores renovaciones generó, en el campo de estudio que me ocupa, provino de las importantes revisiones que se gestaron -en torno de discursos y prácticas- orientadas por los aportes de la historia cultural. La lectura de algunos de los más importantes representantes de las diversas líneas de esta corriente historiográfica -entre ellos Robert Darnton, Carlo Ginzburg, Cliffort Geertz, Peter Burke y, sobre todo, Roger Chartier- propiciaron el ingreso de nuevas formas de problematización crítica que renovaron las tradiciones de estudios sobre el siglo XIX latinoamericano. Por ejemplo, las prácticas sobre lecturas y escrituras fueron indagadas desde las materialidades 
de su circulación (en soportes como los que ofrecían los diarios, los folletos, la edición de lujo parisina, los pliegos sueltos, los cancioneros y almanaques, etc.) y se encabalgaron con reflexiones sobre la experiencia lectora (indiciariamente repuesta a partir de los guarismos de la ampliación del lectorado, los éxitos de venta de las producciones literarias, los registros de préstamos en bibliotecas, etc.) y las mismas representaciones discursivas sobre el asunto (en las escenas de lectura, en las autofiguraciones -más o menos profesionales, más o menos amateurs- de escritores y escritoras, etc.). Las producciones señeras de autores como Adolfo Prieto, Susana Zanetti, Eduardo Romano, Alejandra Laera, Graciela Batticuore, Hebe Molina, Alejandro Parada y William Acree, que vieron la luz durante estos años, permitieron redescubrir zonas de procesos culturales que habían sido desatendidas, y ello gracias a los enfoques iluminadores provenientes de la historia cultural.

En algunos de los artículos de Anclajes se operativizan estas tendencias. En mi trabajo del año 2005, "Las bondades de un juez 'justo': el enmascaramiento oportuno del folletín. (Sobre procesos judiciales y ficciones populares en la Argentina de fines del siglo XIX)" (Vol. 9, N. ${ }^{\circ}$ 9), analicé las tensiones conceptuales entre documento y literatura, a partir del estudio de la novela Juan Moreira de Eduardo Gutiérrez y el expediente criminal levantado contra el sujeto histórico Juan Moreira. El trabajo hipotetizaba sobre las proximidades significativas de dos materialidades verbales diversas (el folletín y las causas judiciales) al momento de representar-dentro de las codificaciones discursivas de cada caso- la corrupción de la vida política en el 80 argentino.

En una ubicación cercana, en este caso desde la historia conceptual -una corriente consolidada en el ámbito rioplatense, gracias a la trayectoria clave de historiadores como Noemí Goldman para el período revolucionario y Jorge Myers para el romanticismo-, el artículo de Dardo Scavino (2019) -"Fluctuaciones de la Independencia en la Carta de Viscardo y Guzmán" (Vol. 23, N. ${ }^{\circ} 1$ )- revisa, precisamente, sopesando los matices que concurren en la "Carta" del criollo peruano y ex jesuita, las ramificaciones de sentidos y tradiciones interpretativas que se reconstituían nocionalmente en la propuesta inaugural de ruptura con España, a partir de las acepciones imperantes en torno a "independencia" y otras categorías como "emancipación" y "pacto".

En el caso de la prensa, un reservorio siempre indispensable para reponer las dinámicas culturales latinoamericanas del siglo XIX, se fueron formalizando en estos últimos veinte años estudios significativos que, para el caso de la experiencia argentina, sondearon críticamente lugares comunes sobre estas prácticas en la experiencia porteña (en los trabajos de Claudia Roman, Hernán Pas, Paula Bruno, Eugenia Molina, Víctor Goldgel) y en otros campos culturales como Córdoba (Andrea Bocco, Paulina Brunetti), Mendoza (Fabiana Varela) y Tucumán (Ana María Risco). Dos artículos de la revista se inscriben en este campo específico. El de Ana María Agudelo Ochoa (2014), "José Joaquín Borda: manifestaciones de una vocación intelectual en el siglo XIX” (Vol. 18, N. ${ }^{\circ}$ ), toma 
como estudio de caso la figura del letrado colombiano - exponente del nacionalismo conservador católico-, para calibrar las interdependencias entre ámbitos de sociabilidad de la cultura local -como El Liceo Granadino y El Mosaico-y la participación concomitante de proyectos en la prensa-El Álbum y El Mosaico-, durante el proceso de afianzamiento de la vida literaria bogotana. Por su parte, la contribución de Juan Ignacio Pisano (2016), "El Torito de los muchachos: lectura de confesiones, escenario de opiniones" (Vol. 20, N. ${ }^{\circ}$ ), relee el recorrido del periódico de Luis Pérez en la arena de lucha que, hacia 1830 en Buenos Aires, las facciones políticas dirimen en su intento por captar la opinión pública desde la prensa. El eje del análisis destaca aquí la enunciación performativa de la confesión como estrategia verbal más idónea, para rearmar el derrotero de este periódico rosista, en tanto pivote que permite desentrañar la circulación pública de la palabra como gestora de la sociedad civil.

Entre las contribuciones de la revista que se detienen en el campo de las escrituras de mujeres, uno de los ámbitos que mayor fuerza ha ido ganando en las últimas tres décadas en los campos culturales y políticos latinoamericanos, encontramos dos trabajos que se insertan en la tradición de estudios dedicados a escritoras y lectoras del siglo XIX, en la senda trazada por Susana Zanetti, Francesca Denegri, Cristina Iglesia, Francine Masiello, Susan Kirkpatrick, María Rosa Lojo, Graciela Batticuore, Mónica Szurmuk y María Vicens. El artículo de Carolina Alzate (2017), "Disciplinando cuerpos y escritura. Agripina Samper sobre George Sand, las mujeres y la literatura (1871)" (Vol. 21, N. ${ }^{\circ} 3$ ), aprovecha esos recorridos para recuperar la figura de la escritora colombiana y, especialmente, analizar una polémica sostenida con José Vergara y Vergara donde, a partir del rechazo o reivindicación de la figura y la obra de George Sand, se dirimía una pulseada por imponer o no el modelo del ángel del hogar para las figuras femeninas, en el contexto del disciplinamiento social del liberalismo contemporáneo.

En el aporte de Hebe Molina (2011), "Lectoras y escritoras en la Argentina de 1860: Margarita Rufina Ochagavía y M. Sasor" (Vol. 15, N. ${ }^{\circ}$ 2), se solapa una doble tarea, el estudio de prácticas -como las de lectura y escritura, visualizadas desde la variable de género- en dos "autoras olvidadas" con escaso abordaje crítico, y, por tanto, también, el rescate de sus textos y la puesta en diálogo actualizada con estas voces femeninas, ignoradas por las distintas legitimaciones intervinientes en la construcción patriarcal del canon literario argentino. Este vital reposicionamiento crítico, con el que colabora este trabajo, fue acompañado por una continua tarea de reedición de textos o publicación de manuscritos inéditos de otras escritoras argentinas decimonónicas -Mariquita Sánchez, Juana Manuela Gorriti, Francisca Espínola, Juana Manso, Eduarda Mansilla, Rosa Guerra, Josefina Pelliza, Lola Larrosa, Raimunda Torres y Quiroga, Ada Elflein, entre otras-, que en las últimas décadas se ubicaron como refundados objetos de estudio.

Como anticipé, existe un bloque de contribuciones en Anclajes que intervienen otros aspectos del canon -en torno a momentos culturales, textos o auto- 
res- sobre los cuales gravita una larga serie de lecturas previas y -gracias a nuevos aparatos críticos, algún sesgo metodológico o la mera incisión interpretativavuelven a tallar las cartas del juego de los sentidos para develar así otras facetas de análisis.

En esta senda, dos artículos rearman estrategias de aproximación al período independentista. Perfilado en la historiografía literaria rioplatense como un momento constreñido a algunas pocas variables -la emergencia de la gauchesca, los estertores del neoclasicismo, la labor perlocutiva de la prensa- las primeras dos décadas del siglo XIX preservan todavía un campo de exploración fértil. En "La condición testimonial de un escritor en transición: Memorias curiosas de Juan Manuel Beruti” (Vol. 19, N. 1), de Virginia Forace (2015), lo que se redimensiona con fino análisis son los recursos discursivos del texto de Beruti y su valor testimonial de largo alcance. A partir de la revisión de aportes variados -desde los clásicos que problematizan la autobiografía, como Philippe Lejeune y Silvia Molloy, hasta la hermenéutica de Paul Ricouer-, el artículo amplifica las posibilidades de lucro de la obra, que tradicionalmente -ya desde los aportes de Adolfo Prieto sobre los memorialistas decimonónicos- aparecía leída casi con exclusividad en relación con el período revolucionario, cuando en verdad avanza generosamente durante toda la primera mitad del siglo XIX. En el caso de María Carolina Domínguez (2016), con "Un diálogo con la tradición clásica latina en la Argentina del siglo XIX: continuidades y rupturas" (Vol. 20, N. ${ }^{\circ}$ 2), también se hace avanzar la mirada, en este caso sobre el peso de la cultura clásica que, en general, aparece anclada como reservorio capital del neoclasicismo pero es desatendida en el período postrevolucionario. Justamente, este trabajo restituye los avatares de esta matriz cultural analizando las disputas en torno de la enseñanza del latín, una polémica continua durante todo el siglo XIX, en las que pueden leerse persistencias y cesuras en la interpretación asignada como componente válido para la formación de los ciudadanos de la nación argentina.

En el caso de Hernán Bergara (2010), su artículo "Condiciones generales para una postergación: El Matadero" (Vol. 14, N. $\left.{ }^{\circ} 14\right)$ se detiene en el texto fundacional de Echeverría, para ensayar hipótesis que permitan comprender los factores intervinientes en la dilación entre el momento de escritura de la obra y los treinta años que median hasta su publicación, intervenida por la mano de Juan María Gutiérrez. A partir de un recorrido por las operaciones protocríticas que Gutiérrez emprende con el relato de Echeverría -las discusiones sobre el carácter de lo ficcional, la lejanía genérica de la ponderación legitimada para la poesía, las aristas violentas del costumbrismo implementado-, se acercan explicaciones tentativas sobre procesos de canonización y valoración general de las ideas reinantes sobre la literatura, esquemas interpretativos que una obra implosiva como $E l$ matadero desmorona a cada paso.

Por último, Sandra Conteras (2019) -en "Lucio V. Mansilla ¿̧hombre de letras?" (Vol. 23, N. ${ }^{\circ} 1$ )- revisa en la trayectoria de Mansilla un tópico tradicionalmente adscripto a los gentlemen del 80 , el supuesto fragmentarismo que 
ya Ricardo Rojas les endilgaba. Para ello agudiza la mirada sobre los diversos ejercicios de acción fronterizos -a veces de difícil discriminación- que el escritor dispersa al participar de la vida letrada (como causeur, escritor, literato, crítico, periodista). Las indefiniciones advertidas en estas estrategias de participación cultural -autogestionadas en la propia discursividad o percibidas así tanto por actores contemporáneos como por críticos posteriores- responderían tanto a las inestabilidades del incipiente campo literario porteńo como a la inscripción -por momentos levemente cínica y snob-con que Mansilla se situaba en la tarea literaria y crítica.

Durante el largo recorrido crítico que todas estas contribuciones fueron socializando, el importante equipo editorial de Anclajes, que ha ido variando su composición con los años, ha sido piloteado por José Maristany y por Graciela Salto, quienes han ocupado alternadamente los cargos de gestión como directores de la publicación. En el trabajo conjunto y cotidiano realizado y la tarea significativa de los evaluadores -labor que han desempeñado voces autorizadas en diversos campos de la crítica- debe buscarse también una de las claves del éxito y de la continuidad de la revista.

No quiero finalizar este breve panorama sobre la presencia de los estudios abocados a las prácticas y discursividades literarias durante el siglo XIX latinoamericano, a lo largo de estos primeros veinticinco números de Anclajes, sin ponderar la relevancia del sostenimiento del proyecto mismo de la revista. Anclajes se ha consolidado como una publicación de rigurosa calidad académica, en el contexto a menudo adverso de las universidades nacionales argentinas y sus políticas editoriales acotadas; desde una ubicación periférica en la Universidad Nacional de La Pampa, ha metabolizado las restricciones propias de un espacio no central, para lograr instalarse como una publicación crítica de consulta indiscutible, cuyos alcances auspiciosos no hacen más que profundizarse con el correr de los años.

Casi como un pastiche jibarizado del brindis - un género discursivo "menor", tan en boga en el ámbito porteño durante la transición del siglo XIX al XX, en el que descollaron Lucio V. Mansilla y Enrique Loncán-, cierro estas notas brindando, a la salud de todos, arengando por la fortaleza en el porvenir de esta revista y la tarea comprometida de quienes a diario la sostienen. 